\title{
Green Literature untuk Menumbuhkembangkan Kesadaran Ekologis di SD Muhammadiyah Program Khusus Bayat, Klaten
}

\author{
Siti Hadiyati Nur Hafida ${ }^{1}$, Akhirul Insan Nur Rokhmah ${ }^{2}$, Ramadhan Bima Kuncara ${ }^{3}$, \\ Vifi Ayu Wardani ${ }^{4}$, Alvin Dwi Novianti, Kartika Yuniandari ${ }^{6}$, Gigih Yulia Sahira ${ }^{7}$, \\ Manarul Hidayat ${ }^{8}$, Amalia Luthfi Yudiantari ${ }^{9}$, Erfin Dwi Fitria Handayani $^{10}$, \\ Almuntaqo Zainuddin ${ }^{11}$ \\ ${ }_{1,2,3,4,5,6,7,8,9,10,11}$ Fakultas Keguruan Ilmu Pendidikan, Universitas Muhammadiyah Surakarta, \\ Indonesia
}

\section{INFORMASI ARTIKEL}

\section{Histori Artikel: \\ Submit: 31 Mei 2020 \\ Revisi: 28 Juni 2020 \\ Diterima: 1 Juli 2020 \\ Publikasi: 4 Juli 2020 \\ Periode Terbit: Juli 2020}

\section{Kata Kunci:}

ekologi sastra,

green literature,

literasi,

reboisasi

\section{Correspondent Author:}

Akhirul Insan Nur Rokhmah

Fakultas Keguruan dan Ilmu Pendidikan

Universitas Muhammadiyah Surakarta,

Indonesia

Email:

a310160169@student.ums.ac.id

\begin{abstract}
ABSTRAK
Kegiatan ini dilatarbelakangi oleh intensitas bencana alam berupa banjir yang cukup tinggi di area Bayat, Klaten sehingga diperlukan adanya kesadaran ekologis sejak dini. Kegiatan ini bertujuan untuk mengidentifikasi adanya pengaruh green literature terhadap kesadaran ekologis di SD Muhammadiyah Program Khusus Bayat. Langkahlangkah yang dilakukan meliputi tiga tahapan yakni 1) Tahap persiapan, 2) Tahap pelaksanaan, dan 3) Tahap evaluasi. Metode yang digunakan adalah metode deskriptif-kualitatif dengan cara advokasi dan difusi IPTEKS. Hasil penelitian ini menunjukkan bahwa pengaruh green literature berbanding lurus dengan tingkat kesadaran ekologis peserta didik di SD Muhammadiyah Program Khusus Bayat. Hal ini ditunjukkan dari karya sastra yang dihasilkan oleh siswa telah mengintegrasikan konsep ekologis. Kesadaran ekologis yang ditanamkan sejak dini sangat diperlukan untuk mengatasi permasalahan bencana alam masa yang akan datang.
\end{abstract}

\section{Pendahuluan}

Kemajuan peradaban manusia seringkali menyebabkan laju transformasi menjadi semakin negatif dan destruktif pada lingkungan alam (Kociszewska, M, 2014). Lingkungan yang pada dasarnya merupakan ruang bagi kehidupan manusia saat ini telah dianggap sebagai objek ekploitasi manusia (Yunansah, H., \& Herlambang, Y. T, 2017) sehingga kondisi lingkungan semakin menurun setiap tahunnya. Salah satu faktor yang mempengaruhi hal tersebut adalah perilaku manusia (Susanti, S., \& Rachmawati, T. S, 2018).

Perilaku manusia yang destruktif diawali dengan adanya paham filosofis konsep alam bebas dan teologis yang menekankan bahwa manusia merupakan spesies utama yang semakin mendorong menurunnya kondisi kesehatan lingkungan (Omoogun, A. C., Egbonyi, E. E., \& Onnoghen, U. N, 2016). Kondisi lingkungan juga semakin diperparah dengan sedikitnya keterlibatan dalam kegiatan perlindungan lingkungan (Boca, G. D., \& Saraçli, S, 2019). Dua kondisi tersebut pada akhirnya semakin menyebabkan kondisi lingkungan mengalami kerusakan. Permasalahan lingkungan juga disebabkan oleh tiga faktor, antara lain: kurangnya tanggungjawab dan pengawasan, kurangnya kurikulum lingkungan yang unik dan kemampuan pedagogi yang tidak efektif (Omoogun, A. C., Egbonyi, E. E., \& Onnoghen, U. N, 2016).

Indonesia merupakan Negara berkembang yang senantiasa berusaha meningkatkan standar dan kualitas hidup masyarakat melalui pembangunan namun, 
seringkali pembangunan tersebut menghambat keseimbangan ekosistem secara luas (Murti, F. N, 2019). Permasalahan lingkungan yang seringkali terjadi di Indonesia adalah kebakaran hutan. Kementerian Lingkungan Hidup dan Kehutanan mencatat luas kebakaran hutan dan lahan dari Januari hingga September 2019 tercatat sebesar 857.756 hektar dan berpotensi mengancam kepunahan satwa liar (Wahid, 2019). Kerusakan ini juga disebabkan oleh rendahnya kesadaran ekologis masyarakat. Krisisnya kesadaran ekologis masyarakat disebabkan oleh sedikitnya pembelajaran ekologis yang diimbangi dengan kepesatan globalisasi di berbagai bidang (Omoogun, A. C., Egbonyi, E. E., \& Onnoghen, U. N, 2016).

Saat ini, tidak akan ada yang menyangkal pentingnya pendidikan lingkungan (Kociszewska, M, 2014). Pemikiran ekologis abad 21 akan menekankan pada tiga poin penting, yaitu: re-integrasi lingkungan dalam kesadaran antropologis dan sosial; kebangkitan ekosistem dari gagasan alam; dan kontribusi penting biosfer terhadap kesadaran planet (Roque, M.-À, 2011). Konsep ekologis abad 21 bertujuan untuk mengurangi kerusakan lingkungan yang ada sehingga kondisi daya dukung maupun daya lenting lingkungan akan membaik.

Berawal dari keprihatinan terhadap budaya eksploitasi alam secara besar-besaran serta kerusakan yang terjadi, upaya penyelamatan kesadaran dapat dilakukan dengan gerakan budaya yang memanfaatkan karya sastra di dalamnya. Gerakan literasi hijau (green literature) merupakan gerakan budaya yang memiliki peran penting dalam membawa misi kehidupan bagi masyarakat (Sabardila, et al., 2020). Green literature merupakan suatu karya sastra yang mempromosikan alam dan melindungi alam dengan menggunakan tatanan bahasa yang menghadirkan kesengsaraan alam, keresahan manusia tentang krisis lingkungan, maupun konservasi alam (Murti, F. N, 2019).

Sastra hijau telah menjadi gerakan sastra di Australia, Amerika, Jepang, Cina, Swiss, Inggris, Belanda, dan Jerman. Gerakan ini awalnya dipelopori oleh William Faulkner, Annie Dillard, dan Emily Dickinson (Pranoto, 2013). Kesadaran ekologis dapat dilakukan dengan mengajak dari strata terkecil yakni anak-anak untuk mampu menyampaikan kritik ekologis melalui sastra. Kesadaran untuk menjaga keseimbangan lingkungan dapat terwujud jika terdapat komunikasi lingkungan yang baik (Susanti, S., \& Rachmawati, T. S, 2018). Anak-anak perlu diberikan pengajaran mengenai sikap dan keterampilan menjaga alam. Salah satu cara membangkitkan minat anak-anak dalam mempelajari kondisi lingkungan dapat dilakukan dengan melakukan kontak langsung sehingga menimbulkan ikatan emosional antara anak dengan alam (Kociszewska, M, 2014).

Komunikasi lingkungan merupakan suatu kesempatan bagi anak-anak untuk memperoleh pengetahuan dan merasakannya secara langsung (Kociszewska, M, 2014). Adanya hubungan yang baik dengan lingkungan dapat mendorong terwujudnya sikap simpati dan empati pada diri anak-anak. Komunikasi lingkungan mampu mendorong dan mengajak setiap orang untuk berperan dalam upaya pengelolaan lingkungan (Susanti, S., \& Rachmawati, T. S, 2018).

SD Muhammadiyah Program Khusus Bayat yang terletak di Kabupaten Klaten merupakan salah satu sekolah terakreditasi A yang telah memiliki berbagai fasilitas untuk mengembangkan bakat dan minat siswa. Tidak hanya unggul dalam bidang keagamaan, berbagai macam olahraga, seni, dan sastra dikembangkan dan seringkali mengikuti lomba antar sekolah dan antar daerah. Setiap tahun sekolah ini menggelar acara Ajang Kreasi Anak yang diharapkan mampu memberikan apresiasi terhadap kemampuan siswa-siswi SD Muhammadiyah Program Khusus Bayat. Tidak hanya itu, setiap tahunnya SD ini juga sering mengikuti berbagai macam lomba literasi seperti mendongeng, menulis puisi, menulis cerpen, menulis syair dan membacakannya.

Kesenian juga sangat berkembang di SD Muhammadiyah Program Khusus Bayat, seperti: seni tari, pantomim, seni musik, dan seni lukis. Lomba literasi seringkali diselenggarakan antar sekolah, dengan tingkat literasi di sekolah yang tinggi. Peserta didik seharusnya lebih mengerti tentang gerakan literasi hijau yang kemudian dikenalkan serta ditanamkan sejak dini agar mampu menghadapi permasalahan bencana alam di kemudian hari.

Karya sastra sendiri merupakan sebuah struktur yang kompleks. Struktur karya sastra itu dinamis melalui tanggapan pembaca seiring berjalannya waktu. Salah satu cara memahaminya perlu untuk dianalisis (Hill dalam Pradopo, 2012). Ekologi sastra merupakan salah satu ilmu interdisipliner dari ilmu ekologi dan kesusastraan, dan juga merupakan ilmu hubungan timbal balik antara tumbuhan dan lingkungannya. Keadaan lingkungan alam yang berpengaruh terhadap kebutuhan hidup manusia sebenarnya juga memengaruhi pendidikan (Setiawan, et al., 2020). Pendidikan memiliki pengaruh yang sangat signifikan terhadap kesadaran ekologis, adaptasi gaya hidup terhadap lingkungan, dan pemodelan perilaku 
konsumerisme (Zsóka, Á., Szerényi, Z. M., Széchy, A., \& Kocsis, T, 2013).

Ekologi sastra merupakan cara pandang tersendiri saat memahami lingkungan hidup dalam perspektif sastra. Ekokritik adalah studi representasi alam dalam karya sastra dan hubungan sastra dengan lingkungan. Sastra merupakan refleksi alam yang dapat menunjukkan kepedulian dan juga mampu memecahkan masalah ekologi (Endraswara, 2016).

Menurut Faizah (dalam Luluk, 2018), gerakan literasi sekolah bertujuan untuk menumbuhkembangkan budaya literasi, meningkatkan kapasitas agar menjadi literat, dan dapat meningkatkan keberlanjutan pembelajaran dengan menghadirkan buku-buku bacaan. Literasi hijau di sekolah akan meningkatkan kesadaran ekologis peserta didik sejak dini, hal ini dapat tercermin dari hasil karya sastra yang telah dibuat. Sebagaimana dalam penelitian (Bernadetta Lisa, 2018) mengembangkan sastra hijau dalam pembelajaran sastra anak yang dijadikan sebagai alternatif dalam gerakan ekologis. Green Literature sebenarnya bukanlah hal yang baru dalam dunia literasi sekolah, namun dalam praktiknya sangat jarang karya sastra disinggungkan dengan alam karena isu-isu sosial dinilai lebih menarik hingga sesuatu yang berbau ekologis menjadi tenggelam dan tidak terlalu diperhatikan.

F.A. Ikhsan, F.A. Kurnianto, H. Apriyanto, E. A. Nurdin, B. W. Bachtiar (2019) dalam penelitiannya yang berjudul "The Effectivity of Environmental Education in Scaffolding Students' Ecological Literacy" memeroleh hasil a significant influence of faculty policy, intructional method, curriculum implementation, etc. towards the students ecological literacy through environmental education as marked by significance level of $0,00<0,005$. Relevansi penelitian ini dengan penelitian F.A. Ikhsan, F.A. Kurnianto, H. Apriyanto, E. A. Nurdin, B. W. Bachtiar adalah keduanya menggunakan pendekatan lingkungan dengan literasi ekologis dalam penelitiannya. Perbedaannya dalam penelitian F.A. Ikhsan menghitung tingkat efektivitas dalam pendidikan berbasis lingkungan, sedang dalam penelitian ini mengenai pengaruh literasi hijau terhadap kesadaran ekologis peserta didik.

Ratnawati (2018) dalam penelitiannya yang berjudul "Implementasi Gerakan Literasi Sekolah di SD Negeri Bhayangkara Yogyakarta" memeroleh hasil SD N Bhayangkara Yogyakarta telah melaksanakan tiga tahap gerakan literasi di sekolah yakni tahap pembiasaan, tahap pengembangan, dan tahap pembelajaran. Relevansi penelitian ini dengan penelitian Luluk Agustin Ratnawati adalah keduanya merupakan gerakan literasi di sekolah. Perbedaannya adalah jika dalam penelitian Luluk Agustin Ratnawati menjelaskan tentang terlaksananya gerakan literasi sekolah dengan tiga tahapan, sedangkan dalam penelitian ini menggunakan gerakan literasi berbasis ekologis (green literature).

Dewojati (2018) dalam pengabdiannya yang berjudul "Pengembangan Pembelajaran Penulisan Kreatif Berwawasan Lingkungan Bidang Bahasa dan Sastra Indonesia bagi Guru dan Siswa Pondok Pesantren Muqimus Sunnah di Palembang" memeroleh hasil pelatihan penulisan kreatif yang diwujudkan dalam games sastra dan lingkungan sangat diperlukan kekritisan dan kreativitas baik guru maupun siswa dalam dunia literasi. Relevansi pengabdian ini dengan pengabdian Dewojati adalah keduanya mengaitkan sastra dengan lingkungan, sedangkan perbedaannya adalah dalam pengabdian ini menganalisis pengaruh dari green literature terhadap kesadaran ekologis sedangkan dalam pengabdian Cahyaningrum Dewojati lebih mengedepankan pada pembelajaran dan pelatihan menulis kreatif.

Suwandi (2017) dalam penelitiannya yang berjudul "Ecological Intellegence Values in Indonesian Language Textbooks for Junior High School Students" memperoleh hasil bahwa The ecological intellegence values in BI textbooks are found in materials or readings, assignments, or evaluation. The strengths of the books are the materials of biotics and abiotics environments are rich and able to provide students, the types of selected texts are interesting to be correlated with environment governance, and fable is an appropriate medium for student character building. Relevansi penelitian ini dengan penelitian Suwandi adalah keduanya mengembangkan ekologi. Perbedaannya adalah jika dalam pengabdian ini meneliti pengaruh dari green literature terhadap kesadaran ekologis peserta didik SD Muhammadiyah Program Khusus Bayat, sedangkan dalam penelitian Suwandi meneliti tentang kecerdasan nilai ekologi dalam buku teks berbahasa Indonesia.

Yunansah (2017) dalam penelitiannya yang berjudul "Pendidikan Berbasis Ekopendagogik dalam Menumbuhkan Kesadaran Ekologis dan Mengembangkan Karakter Siswa Sekolah Dasar" memperoleh hasil bahwa pendidikan berbasis pendekatan ekopendagogik adalah pendekatan yang berorientasi pada upaya multidomain siswa. Relevansi penelitian ini dengan penelitian Yunansah adalah keduanya menggunakan alam sebagai objek 
penelitiannya. Perbedaannya adalah dalam penelitian ini meneliti tentang pengaruh green literature terhadap kesadaran ekologis sedangkan dalam penelitian Yunansah meneliti pendidikan berbasis ekopendagogik.

Syachruddin (2019) dalam pengabdiannya yang berjudul "Pelatihan Teknik Penelitian Ekologi pada Siswa dan Guru Biologi MAN 2 Kota Mataram Nusa Tenggara Barat" menghasilkan simpulan siswa dan guru biologi MAN 2 perlu ditingkatkan pemahaman penelitian ekosistem yang difokuskan pada proposal dan aplikasi. Relevansi penelitian ini dengan penelitian adalah keduanya menggunakan basis ekologi dalam pengabdiannya. Perbedaannya adalah dalam penelitian ini berbasis green literature serta perngaruhnya terhadap kesadaran ekologis siswa sedangkan dalam penelitian ini memfokuskan pada proposal dan aplikasi.

Tujuan dari pengabdian ini adalah untuk mengidentifikasi pengaruh green literature terhadap kesadaran ekologis di SD Muhammadiyah Program Khusus Bayat, selain itu dengan adanya kegiatan pengabdian ini diharapkan peserta didik semakin sadar akan pentingnya menjaga dan menyayangi alam. Membangun generasi penerus bangsa yang sadar dan peka akan lingkungan sangat penting untuk Indonesia yang lebih baik di tengah kemajuan teknologi (Ratih, et al., 2019). Keseimbangan antara ekologis dengan teknologi perlu diterapkan agar tidak terjadi permasalahan baik bencana maupun kerusakan alam. Adanya peningkatan kesadaran lingkungan dapat mendorong upaya minimalisasi penyalahgunaan lingkungan dan sumberdayanya (Omoogun, A. C., Egbonyi, E. E., \& Onnoghen, U. N, 2016).

\section{Metode Pelaksanaan}

Kegiatan ini dilaksanakan dengan cara advokasi dan Difusi IPTEKS (Ilmu Pengetahuan, Teknologi dan Seni) dimana peserta didik akan didampingi dalam pembuatan karya sastra berbasis green literature kemudian karya sastra tersebut menghasilkan sebuah antologi puisi yang dapat dijadikan ketentuan untuk mendasari adanya kesadaran ekologis peserta didik.

Penelitian ini menggunakan pendekatan deskriptif-kualitatif. Pendekatan kualitatif merupakan metode untuk mengeksplorasi dan memahami makna yang dianggap berasal dari masalah sosial dan kemanusiaan (Cresswell, 2017). Hasil akhir dalam penelitian kualitatif tidak hanya menghasilkan informasi yang tidak dapat diperoleh melalui penelitian kuantitatif, namun juga harus membantu mengatasi masalah dan meningkatkan taraf hidup manusia (Sugiyono, 2017).

\section{Hasil Pelaksanaan dan Pembahasan}

Hasil dari pelaksanaan kegiatan ini diharapkan peserta didik SD Muhammadiyah Program Khusus Bayat mampu memiliki kemampuan literasi yang berbanding lurus dengan kesadaran ekologis. Peserta didik diberikan pengarahan tentang apa dan bagaimana green literature. Saat pengarahan berlangsung seluruh peserta didik mengerti apa yang disampaikan oleh pengarah sehingga peserta didik memiliki gambaran bagaimana akan merealisasikannya dalam bentuk green literature. Hal tersebut sesuai dengan Yunansah, H., \& Herlambang, Y. T (2017) yang menyatakan bahwa pembelajaran dapat menjadi salah satu langkah penyampaian permasalahan lingkungan, karena pembelajaran harus mampu memberikan pemahaman multidomain, tidak hanya kognitif saja melainkan juga afektif dan psikomotorik

Peserta didik kemudian diberikan waktu untuk membuat karya sastra berupa puisi yang bewawasan lingkungan, semuanya mampu merefleksikan tentang bumi dan kerusakannya, 98\% dari peserta didik sudah menggunakan majas dan diksi yang bermaksud untuk mengajak pembaca untuk sadar berekologis secara langsung maupun tidak langsung. Seperti pemakaian kata "Marilah" "Ayolah!" dan lain sebagainya. 20\% dari peserta didik di SD Muhammadiyah Program Khusus Bayat juga memiliki kemampuan untuk memetaforakan kerusakan alam sebagai benda hidup yang berperasaan hal ini dapat tercermin dalam sajak yang memetaforakan bumi yang "merasakan sakit" dan "menangis".

Penggunaan diksi cukup sederhana sehingga mudah diserap oleh pembaca awam sekalipun. Tidak hanya itu, $10 \%$ dari peserta didik juga mampu memberikan puisi yang bersifat solusi seperti penyebutan diksi 'reboisasi' atau pun 'penanaman kembali' nampak jelas tertulis di dalam baitnya. Peserta didik juga telah mampu membandingkan realitas bumi ketika belum terjadi kerusakan dan telah mengalami kerusakan. Walaupun deskripsi terlihat sederhana, namun jelas tertera dalam setiap baitnya. Kendala dalam pembuatan green literature adalah rawannya peserta didik untuk melakukan plagiat karena banyak puisi-puisi yang ada di dalam buku pelajaran, sehingga diperlukan pengawasan saat melaksanakan pembuatan karya.

Setelah menyusun karya sastra untuk merealisasikan kesadaran ekologis peserta didik di SD Muhammadiyah Program Khusus Bayat, pengarah dan peserta didik melakukan penanaman pohon bersama sebagai suatu bentuk perlindungan alam dan rasa cinta 
terhadap alam. Upaya penanaman pohon juga merealisasikan green school sehingga sekolah menjadi lebih rimbun. Penanaman dilakukan dalam area sekolah dengan menggunakan peralatan seadanya. Kendala dalam melaksanakan kegiatan penanaman pohon adalah diperlukannya banyak botol bekas sebagai sarana penempatan bibit tanaman.

Pengabdian ini relevan dengan pentingnya pendidikan ekologi yang disampaikan oleh Wensing and Carlos dalam Betha Handini, Nurul Fatimah dan Totok Rochana (2017), 'knowledge systems for sustainable development and sustainability as the best provide solutions so too the ecology of education is openended' (sistem pengetahuan untuk pembangunan berkelanjutan merupakan solusi terbaik begitu juga pendidikan ekologi yang bersifat terbuka). Melalui pengabdian ini, terlihat bahwa telah terbentuk perilaku green literature di SD Muhammadiyah Program Khusus Bayat dan peserta didik telah mampu menyusun karya sastra dengan memberikan solusi terhadap permasalahan lingkungan.

Berikut dipaparkan bagan pelaksanaan dari pengabdian:

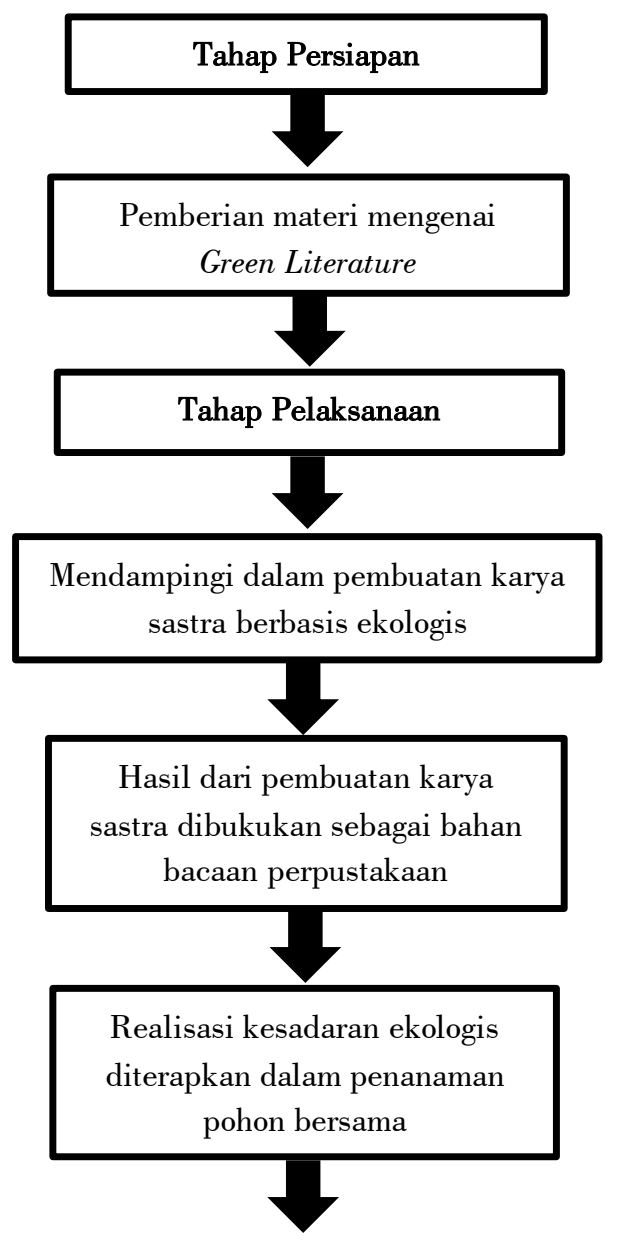

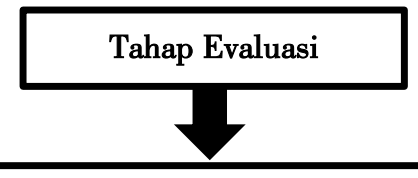

Evaluasi penanaman pohon dilaksanakan secara bersama-sama dilanjutkan dengan identifikasi karya sastra berbasis lingkungan

\section{Tahap Persiapan}

Pada tahap persiapan ini dilakukan pemberian materi green literature. Urgensi dalam tahap ini adalah pengarah perlu menguasai materi dan mampu menjelaskannya kepada peserta didik beserta contohcontoh yang diperlukan. Materi yang diberikan seputar informasi terkait keadaan alam yang sebenarnya sedang terjadi (realitas alam), berbagai macam bentuk bencana alam, penyebab serta solusi yang ditawarkan. Pengarah juga harus mencontohkan cara merefleksikannya dalam bentuk green literature.

\section{Tahap Pelaksanaan}

Pelaksanaan terbagi menjadi tiga tahap. Tahap pertama adalah mendampingi dalam pembuatan karya sastra berbasis ekologis. Tahapan ini menuntut pengarah untuk memancing kreativitas peserta didik serta mengawasi proses pembuatan karya sastra bersih dan bebas dari kecurangan dalam bentuk apapun termasuk segala bentuk plagiasi.

Tahap kedua adalah tahap pembukuan. Karya sastra dikumpulkan dalam satu buku untuk mempermudah proses identifikasi pada tahap selanjutnya. Selain itu, pada tahap ini juga bermanfaat untuk menambah perbendaharaan perpustakaan sekolah. Tahap terakhir pelaksanaan adalah penanaman pohon bersama. Suatu bentuk realisasi kesadaran ekologis dapat dilatih menggunakan penanaman pohon bersama, pelatihan menanam pohon ini bisa dijadikan penyulut untuk diteruskan ke masyarakat.

\section{Tahap Evaluasi}

Tahap terakhir dari serangkaian pengabdian ini adalah evaluasi, dimana evaluasi dilakukan agar kelak jika peneliti yang lain akan melanjutkan pengabdian bisa menjadi lebih efektif dan efisien. Tahap ini juga dilakukan identifikasi karya sastra untuk menemukan penanda green literature sebagai acuan kesadaran ekologis peserta didik. Pada tahap evaluasi ini, pengarah menemukan bahwa peserta didik telah mengintegrasikan pengetahuan ekologis dalam setiap 
karya sastranya, bahkan peserta didik mampu memberikan solusi terhadap permasalahan lingkungan yang ada tersebut.

\section{Simpulan}

Berdasarkan hasil dan pembahasan yang telah diperoleh, dapat disimpulkan bahwa peserta didik SD Muhammadiyah Program Khusus Bayat memiliki kemampuan green literature tinggi. Kegiatan ini dilaksanakan menggunakan tiga tahapan yakni tahapan persiapan yang berisi pemberian materi green literature; tahap pelaksanaan yang berisi pembuatan karya sastra berbasis green literature, pembukuan, dan penanaman pohon bersama di akhir tahap pelaksanaan.

Tahapan terakhir adalah tahap evaluasi yakni mengidentifikasi karya sastra untuk menemukan penanda green literature sebagai acuan kesadaran ekologis peserta didik. Hasil pengabdian menunjukkan bahwa green literature berbanding lurus dengan kesadaran ekologis. Hal ini dapat dilihat dari pemilihan diksi dalam karya sastra serta realisasi penanaman pohon yang dilaksanakan secara bersama-sama. Pemahaman green literature yang dimiliki oleh peserta didik lebih mudah dilakukan jika peserta didik mengetahui kondisi lingkungan secara langsung. Hal tersebut sesuai dengan Du, Y., Wang, X., Brombal, D., Moriggi, A., Sharpley, A., \& Pang, S (2018) yang menyatakan bahwa tempat tinggal memiliki pengaruh yang cukup besar terhadap kesadaran lingkungan, khususnya anak-anak. oleh karena itu, langkah-langkah pengelolaan lingkungan akan lebih baik jika diterapkan secara lokal.

Undang-Undang Nomor 32 Tahun 2009 tentang Perlindungan dan Pengelolaan Lingkungan menekankan bahwa dengan adanya kearifan lokal maka upaya melindungi dan mengelola lingkungan akan lebih mudah lestari dengan memperhatikan nilai-nilai luhur yang ada. Kearifan lokal akan lebih mudah diimplementasikan oleh peserta didik jika diintegrasikan dalam proses pembelajaran. Adanya upaya pengintegrasian konsep ekologis dalam mata pelajaran dapat mendorong peningkatan kesadaran tentang permasalahan lingkungan (Purnami, W., Utama, W. G., \& Madu, F. J, 2016).

\section{Daftar Pustaka}

AR, Syahruddin., Imam Bachtiar, Wayan Merta, Kusmiyati. 2019. "Latihan Tentang Teknik Penelitian Ekologi pada Siswa dan Guru Biologi MAN 2 Kota Mataram Nusa Tenggara Barat"
Jurnal Pendidikan dan Pengabdian Masyarakat. 2(2). 311-316.

Boca, G. D., \& Saraçli, S. (2019). Environmental Education and Student's Perception, for Sustainability. Sustainability (Switzerland), 11(1553), 1-18. https://doi.org/10.3390/su11061553

Cresswel. John W. 2017. Research Design Pendekatan Kuantitatif, Kualitatif dan Mixed. Yogyakarta: Pustaka Pelajar.

Dewojati, Cahyaningrum. 2018. "Pengembangan Pembelajaran Penulisan Kreatif Berwawasan Lingkungan Bidang Bahasa dan Sastra Indonesia bagi Guru dan Siswa Pondok Pesantren Muqimus Sunnah di Palembang" Bakti Budaya. 1(1). 45-56.

Du, Y., Wang, X., Brombal, D., Moriggi, A., Sharpley, A., \& Pang, S. (2018). Changes in Environmental Awareness and Its Connection to Local Environmental Management in Water Conservation Zones: The Case of Beijing, China. Sustainability (Switzerland), 10(2087), 1-24. https://doi.org/10.3390/su10062087

Endraswara, Suwardi. 2016. Sastra Ekologis Teori dan Praktik Pengkajian.Yogyakarta:CAPS (Center for Academic Publishing Service).

Ikhsan, F.A., F.A. Kurnianto, B. Apriyanto., E. A. Nurdin., R.W. Bachtiar. 2019. "The Efectivity of Environmental Education in Scaffolding Students' Ecological Literacy" Jurnal Pendidikan IPA Indonesia. 8(3). 398-406.

Kociszewska, M. (2014). Ecological Awareness and Education of The Society in The Light of Sustainability Idea - Selected Aspects. Pedagogika Rodziny, 4(1), 31-41. https://doi.org/10.2478/fampe-2014-0004

Murti, F. N. (2019). Indonesia's Green Literature: “The Sleeping Beauty" Literary. IOP Conference Series: Earth and Environmental Science, 243(012165). https://doi.org/10.1088/1755$1315 / 243 / 1 / 012165$

Omoogun, A. C., Egbonyi, E. E., \& Onnoghen, U. N. (2016). From Environmental Awareness to Environmental Responsibility: Towards a Stewardship Curriculum. Journal of Educational Issues, $\quad 2(2), \quad 60-72$. https://doi.org/10.5296/jei.v2i2.9265

Permatasari, Bernadetta Lisa Andika. 2018. "Sastra Hijau dan Pembelajaran Sastra Anak: Alternatif Gerakan Ekologis dalam Puisi" Halauan Sastra Budaya. 2(2). 187-203.

Pradopo, Rachmat D. 2012. Beberapa Teori Sastra, Metode Kritik, dan Penerapannya. Yogyakarta:Pustaka Pelajar. 
Pradana, Batha Handini., Nurul Fatimah, Totok Rochana. 2017. "Pelaksanaan Gerakan Literasi Sekolah Sebagai Upaya Membentuk Habitus Literasi Siswa di SMA N 4 Magelang" Solidarity. 6(2).167-179.

Pranoto, Naning, Soesi Sastro, Sides Sudyarto DS. 2013. Seni Menulis Sastra Hijau bersama Perhutani. Jakarta:Perhutani.

Purnami, W., Utama, W. G., \& Madu, F. J. (2016). Internalisasi Kesadaran Ekologis Melalui Pengelolaan Sampah di Lingkungan Sekolah Dasar. Seminar Nasional Pendidikan Sains, 487-491. Retrieved from https://media.neliti.com/media/publications/173 947-ID-internalisasi-kesadaran-ekologismelalui.pdf

Ratih, K., Prayitno, H. J., Sutopo, A., Tamatea, L., \& Syahriandi, M. (2019). Preparing for Quality EFL Teachers: The Disjuncture Between Policies and Practice in The Internet Communication Technology (ICT) Use in Classroom Context.

Ratnawati, Luluk Agustin. 2018. "Implementasi Gerakan Literasi Sekolah di SD Negeri Bhayangkara Yogyakarta" Jurnal Pendidikan Guru Sekolah Dasar. 36(7).

Roque, M.-À. (2011). Ecological Science and Ecological Awareness. Quaderns de La Mediterrània, 16, 11-15. Retrieved from https://www.iemed.org/observatori-en/areesdanalisi/arxius-adjunts/qm-16originals/roquema_ecological science and awarness_qm16.pdf/at_download/file

Sabardila, A., Budiargo, A. D., Wiratmoko, G., Himawan, J. A., Triutami, A., Intansari, A., ... \& Suistri, S. (2020). Pembentukan Karakter Peduli Lingkungan melalui Kegiatan Penghijauan pada Siswa MIM Derasan Sempu, Boyolali. Buletin KKN Pendidikan, 1(2).

Setiawan, F. A., Arisanty, D., Hastuti, K. P., \& Rahman, A. M. (2020). The Effect of Metacognitive Ability on Learning Outcomes of Geography Education Students. Indonesian Journal on Learning and Advanced Education (IJOLAE), 2(2), 82-90.

Sugiyono. 2017. Metode Penelitian Pendidikan Pendekatan Kualitatif, Kuantitatif, dan R\&D. Bandung: Alfabeta.

Susanti, S., \& Rachmawati, T. S. (2018). Menumbuhkan Kesadaran Hidup Ekologis melalui Komunikasi Lingkungan di Eco Learning Camp. Mediator: Jurnal Komunikasi, $11(2)$, 188-202. https://doi.org/10.29313/mediator.v1li2.3961
Suwandi, Sarwiji., Ahmad Yunus., dan Laili Etika Rahmawati. 2017. "Ecological Intellegence Values in Indonesian Language Textbooks for Junior High School Students" Pertanika Journal Social Sciences and Humanities. 25(S). 237-248.

Wahid, A. 2019. BNPB: Karhutla 2019 Bakar 857 Ribu Ha, Terparah dalam 3 Tahun. URL: https://www.detik.com/news/berita/d4755492/bnpb-karhutla-2019-bakar-lahan-857ha-terparah-dalam-3-tahun. Diakses pada tanggal 28 Februari 2020.

Undang-Undang No 32 Tahun 2009 tentang Perlindungan dan Pengelolaan Lingkungan Hidup

Wensing, E. J., Calos A. Torre. 2009. "The Ecology of Education: Knowledge Systems for Sustainable Development and Sustainability" Journal of Teacher Education for Sustainbility. 11(1). 3-17.

Yunansah, H., \& Herlambang, Y. T. (2017). Pendidikan Berbasis Ekopedagogik dalam Menumbuhkan Kesadaran Ekologis dan Mengembangkan Karakter Siswa Sekolah Dasar. EduHumaniora | Jurnal Pendidikan Dasar, $9(1)$, 27-34. https://doi.org/10.17509/eh.v9i1.6153

Zsóka, Á., Szerényi, Z. M., Széchy, A., \& Kocsis, T. (2013). Greening due to Environmental Education? Environmental Knowledge, Attitudes, Consumer Behavior and Everyday Pro-environmental Activities of Hungarian High School and University Students. Journal of Cleaner Production, 48, 126-138. https://doi.org/10.1016/j.jclepro.2012.11.030 